\title{
The Development of Emotional Intelligence Scale in Sport Coaching
}

\author{
Seunghyun Hwang ${ }^{1}$, Boram Kim ${ }^{1}$, \& Hoseok Kang ${ }^{2 *}$ \\ ${ }^{1}$ Kyungpook National University \& ${ }^{2}$ Korea Squash Federation
}

\begin{abstract}
[Purpose] The purpose of this study was to develop the Emotional Intelligence Scale in Sport Coaching(EISSC) based on the emotional intelligence trait model. [Methods] The participants were 236 professional sports coaches by the purposive sampling methods via e-mails. 48 preliminary items were developed by literature review among expert panels. Then, a total of 40 items were selected after the item-analysis. Exploratory factor analysis was conducted for construct validity and criterion validity was evaluated by Person's correlation with coaching efficacy scale and general emotional intelligence scale. An internal consistency, Cronbach's alpha coefficient, was used to see the reliability. [Results] The results of exploratory factor analysis presented a six sub-structure factors (Self-awareness, Awareness of others, Optimism, Utilization of emotion, Emotion regulation, Social skills) with 20 items, which explained $68.49 \%$ of the total variance. Criterion-related validity was supported by correlations with in coaching efficacy $(r=.713)$ and general emotional intelligence( $(\mathrm{r}=.647)$. Reliabilities were secured with Cronbach's alpha coefficient .854 for the total 20 items. [Conclusions] The EISSC can be used to provide an valid measure of emotional ability of coaches in sport.
\end{abstract}

Key words: Coach-athlete relationship, Emotional ability, Sport coaching, Elite sports, Factor analysis, Scale

\section{서 론}

전문 운동선수와 지도자는 한 팀 내에서 유기적인 인간관 계를 형성해간다. 공동의 목표를 위한 협력관계 그리고 그 협 력관계를 이끄는 지도자의 리더십은 팀의 원활한 운영 그리 고 좋은 경기성적을 위해서 꼭 필요한 요소이다. 하지만 유기 적인 인간관계 속에는 상호 간의 행동적, 인지적, 그리고 심 리적(정서적) 요소들이 모두 역동적으로 연관되어 있어서 효 율적인 코칭행동(리더십)을 단편적으로 개념화하기에는 매 우 어렵다. 그러한 이유로 효율적인 리더의 행동을 형성하는

논문 투고일 : 2021. 03. 02.

논문 수정일 : 2021. 03. 11.

게재 확정일 : 2021. 03. 19.

* 교신저자 : 강호석(khsquash@naver.com)

* 본 연구는 2018학년도 경북대학교 신임교수정착연구비에 의 하여 연구되었음(201853990000).
개인의 특성이 무엇인지에 관한 연구는 국내외 다양하게 진 행되고 있다. 그중 정서지능(Emotional Intelligence)의 개 념은 효율적인 리더의 중요한 특성으로 인식되어 많은 연구 가 진행되어 왔다.

일반적으로 정서지능은 자신 그리고 타인의 감정을 잘 인 식, 표현, 이해, 그리고 조절하는 개인의 특성적 능력으로 정 의 된다(Goleman, 1995). 이러한 개인의 정서지능은 촉진 적인 사회적 관계 그리고 조직의 효율성 등의 주제로 성격 및 조직심리학 분야에서 많은 연구가 진행되어왔다. 특히, 조직 심리학 분야에서는 리더의 정서지능은 효율적인 리더십의 중요한 측면이고 훌륭한 $\mathrm{CEO}$ 들의 개인적 특성이라는 연구 결과들이 발표되고 있다(Caruso, Mayer, \& Salovey, 2002; Kobe, Eiter-Palmon \& Rickers, 2001; Rosete \& Ciarrochi, 2005).

기업의 리더와 마찬가지로 스포츠지도자에게 정시지능 
은 중요하게 작용된다. 스포츠종목 코치 또한 한 조직 (팀)의 리더 역할을 수행하며 선수들의 기술지도, 선수들의 훈련 관리, 그리고 시합 준비 등과 동시에 가장 가까운 선수들의 심리적 조력자 역할을 수행한다(Feltz, Chase, Moritz \& Sullivan, 1999). 스포츠 팀 이라는 하나의 조직 속에서 지 도자는 많은 역할을 수행하며 팀을 리드해야한다. 즉, 스포 츠 팀 지도자는 선수들에게 적절한 동기부여를 하며, 서로 의 상황을 존중하며, 효율적인 의사소통을 이끌고, 수행의 결과에 대해 격려를 하는 등의 성격적 그리고 행동적 특성이 존재하고 이는 팀의 효율성(Team Effectiveness) 및 코칭 효율성(Coaching Effectiveness)에 중대한 영향을 미친다 (Horn, 2008).

스포츠지도자의 정서지능 중요성은 실제 코칭 상황을 통 해 보고되고 있다. 실제 경기 중 대부분 코치들은 긴장되고 불안해하는 모습이 실제 관찰되며 선수들의 경기력을 위해 자신의 정서 상태를 조절해야 할 필요가 있다. 예를 들어, Gould, Guinan, Greenleaf와 Chung(2002)은 올림픽 레벨 코치들을 대상으로 한 조사연구에서 자신의 정서상태 를 조절하고 때론 자신의 정서 상태를 숨기는 능력이 코칭 능력의 한 부분이라고 보고하였다. Grace(1988)는 성공적 인 코치가 되기 위해서는 선수들의 신체적 그리고 정서적인 요구에 민감하게 반응해야 한다고 주장하였다. 또한 미국 대학 농구 리그의 전설적인 존 우든(John Wooden) 감독은 그의 저서 `우든의 리더십(Wooden on Leadership)'에서 감정적인 코칭(Emotionalism)은 비일관적인 코칭 행동을 야기하며 선수 그리고 팀의 수행력에 부정적인 영향을 미친 다고 회고하고 있다(Wooden \& Jamison, 2005).

스포츠지도자들이 경험하는 정서와 관련된 기능적인 능 력 즉, 지도자 자신 그리고 선수들의 정서를 잘 인지하고 대 처하는 것은 팀과 선수를 이끄는 중요한 특징이라고 일관적 으로 보고하고 있다. 이를 위해 코치들의 정서적인 측면에 대한 국내외 연구자들의 관심이 늘어나고 있다. 국내의 경 우 선수들의 정서지능에 관한 연구(예, Choi \& Kim, 2014; Jang \& Kim, 2019; Lee, Nam \& Kim, 2012)비해 스포츠지도자의 정서지능 연구는 잘 개발되지 못하였다. Kim과 Choi(2014)는 축구선수들이 지각하는 지도자의 변 혁적 리더십과 정서지능 연구를 통해 정서지능은 변혁적 리 더십과 선수 만족에 긍정적인 영향을 미치는 것으로 보고하 였다. 스포츠지도자의 정서지능은 직접적인 측정이 아닌 지 도자의 정서적 역량을 강조하는 감성적 리더십(Goleman,
Boyatezis \& Mckee, 2002)을 중심으로 연구가 이루어지 고 있다. 예를 들어, $\mathrm{Oh}(2008)$ 는 테니스지도자의 감성 리 더십과 지도효율성과의 정적인 상관관계를 보고하고 있고, $\operatorname{Kim}(2012)$ 은 선수들의 정서 상태에 정적인 영향을 미치는 요인으로 엘리트 스포츠 지도자의 감성적 리더십을 보고 하 였다. 하지만 감성적 리더십은 정서지능과는 유사한 측면이 있으나 행동적인 영역에 초점을 맞추고 있어 개인의 특성적 능력을 측정하고 평가하는 '정서지능' 과는 다른 측면이 있다. 국외 경우, 보다 직접적으로 지도자들의 정서지능을 측정 하고 연구에 활용하고자 하는 시도가 늘어가고 있다. 구조방 정식 모형을 통해서 예측변인으로 정서지능은 코칭효능감 (Coaching Efficacy)과 리더십 행동에 긍정적인 영향을 미 치는 것으로 밝혀졌다(Hwang, Feltz \& Lee, 2013). 보다 구체적으로, Thelwell, Lane, Weston과 Greenlees(2008) 의 연구에서 정서규제능력은 동기효능감(Motivation Efficacy), 긍정정서유지능력은 인성발달효능감(Character Building Efficacy), 그리고 정서인식능력은 지도효능감 (Teaching Efficacy)를 정적으로 예측하는 것으로 보고 하 였다. Watson과 Kleinert(2018)는 스포츠지도자의 정서지 능과 선수들의 기본욕구만족(Basic need satisfaction)간 의 관계를 다층모형분석(Multilevel analysis)을 통해 검증 하여 지도자의 정서통제는 선수들의 유능감 만족을 유의미하 게 예측하였으며 지도자의 정서적 웰빙 또한 선수들의 자율 성 지지에 유의미한 상관성을 보고하였다. Kim, Hwang \& $\operatorname{Kim}(2020)$ 은 태권도 선수들이 지각하는 지도자의 정서지능 과 코칭행동 연구에서 높은 수준의 정서지능은 자율성지지 코칭행동뿐만 아니라 선수들의 심리욕구만족도 더 강하게 예 측하는 것으로 보고하였다. 이러한 결과들은 지도자 자신들 뿐만 아니라 선수들의 정서상태를 잘 인지하고 효율적으로 관리하는 지도자의 특성적 능력은 선수들의 수행력과 팀 분 위기 그리고 지도자 리더십에 긍정적인 영향을 미친다.

위에 언급된 선행연구들은 정서지능을 측정하기 위해 성 격 및 조직심리학 분야에서 개발된 척도를 주로 사용하여 연 구 결과의 타당성에 다소 문제가 있을 수도 있다. 조직의 리 더로서의 특성만을 고려하기보다는 좀 더 구체적인 스포츠 코칭상황에 적합한 정서지능척도 개발이 요구되어진다 (Hwang et al., 2013; Meyer \& Flecher, 2007).

본 연구는 심리학적 변인의 측정도구를 개발하는 것이므 로 본 연구의 방향에 적절한 정서지능에 대한 이론과 개념에 대한 좀 더 깊은 이해는 필연적이다. Mathew, Zeidner와 
Roberts(2007)는 척도의 신뢰도와 타당도를 위해서 충분 한 이론적 개념의 이해, 개념의 하위 구성요소, 그들의 양적 그리고 질적인 관계에 대한 심도 있는 문헌 고찰이 요구된다 고 주장한다.

정서지능에 두 가지 구별되는 이론적 모형은 정서지능을 인지적인 능력으로 간주하는 능력모형(Ability Model)과 개 인의 특성으로 간주하여 개념화하는 특성모형(Trait Model) 이 있다. 능력모형을 기반으로 한 척도는 문항의 정답과 오답 있는 능력평가 방식 (Maximum Performance Test)을 사용 한다. 반면, 특성모형을 기반으로 한 척도들은 일반적인 성격 검사와같은자기보고식 평가방법(Self-Reported Assessment) 을 사용한다.

정서지능을 개인의 인지적 능력으로 개념화한 능력모형 과는 상반되게 특성모형은 이를 개인의 성격적 특성으로 설 명 한다(Neuhauer \& Freudenthaler, 2005). Bar-On (1997)은 정서지능을 인간의 정서와 연관된 환경적 요구에 잘 대처하되 영향을 미치는 일련의 비인지적 능력, 유능감, 그리고 기술이라고 정의한다. 이를 바탕으로 Bar-On은 15 가지의 세부 구성요소를 주장하며 113 문항의 척도를 개발 했다. 이것이 통상적으로 알려진 정서지수(EQ)이다. 하지만 이는 심리측정학적으로 불안전한 구조이며 정서지능과는 다 소 차이가 있는 하위요인들(예, 문제해결, 현실성 검증) 로 구성되어 있다는 비판을 받는다(Perez, Petrides \& Furnham, 2005; Petrides \& Furnham, 2001; 2004). 그 후 Schutte 등(1998)은 정서지능을 자신과 타인과의 관계 속에서 발생되는 정서가 연관된 일련의 정보들을 잘 처리하 고 이용하는 것이 특성적인 높은 수준의 정서지능이라고 하 였다. 이를 위해 Schutte 등(1998)은 세 가지 하위요인, 즉 정서평가, 사용, 그리고 규제를 포함한 33개 문항의 정서지 능 척도 (Emotional Intelligence Scale: EIS)를 개발하였 고 .78의 높은 검사-재검사 신뢰도와 .90의 내적일관도를 보고하였다. 이 척도는 측정의 편이성으로 여러 학문영역에 서 많이 사용되고 있다. 그 후 Austin, Saklofske, Huang \& McKenny(2004)는 기존 척도의 단점을 보완하여 41문 항의 수정된 정서지능척도를 발표하였다. 또한 Petrides와 Furnham (2004)는 특성정서지능질문지(Trait Emotional Intelligence Questionnaire: TEIQue)를 개발하였다. 하 위척도로 웰빙, 자아규제, 사회성, 감정적 성향이 구성되었 으며 153 문항과 30 문항 (축약형)이 동시에 개발되어 널리 사용되고 있다. 척도의 내적일관도는 .85로 보고되고 있다.
엘리트 스포츠지도자들의 정서지능은 기업의 리더와는 차별화된 개념적 구조를 가지고 있으며 스포츠팀을 코칭 및 관리하는데 매우 중요한 비중을 차지하기 때문에 타당한 척 도개발의 필요성이 제시되고 있다(Chan \& Mallett, 2011). 따라서 본 연구의 목적은 정서지능의 특성모형을 기 반으로 스포츠 현장과 코칭상황에 특성화된 스포츠코칭 정 서지능 측정도구(Emotional Intelligence Scale in Sport Coaching: EISSC)를 개발하여 개발된 척도의 구조적 타당 성과 준거타당도를 검증하는 것이다.

\section{연구방법}

본 연구의 목적은 스포츠 특성에 맞는 코치의 '정서지능' 을 이론화하여 타당한 측정도구를 개발 - 검증하는데 있다. 이를 위해 '스포츠코칭정서지능' 척도 개발과정은 크게 3 단 계로 1)예비문항 구성 2)자료수집 3)분석절차 로 구분된다.

\section{예비문항구성}

‘스포츠코칭정서지능' 척도 개발을 위한 예비문항 구성은 국내외 선행연구에서 사용된 정서지능의 특성모형을 기반 으로 개발된 일반인 또는 교사 대상 정서지능척도(Cho \& Kang, 2016; Jang \& Kim, 2019; Lim, 2013; Petrides \& Furnham, 2004; Schutte et al., 1998; Wong \& Law, 2002)의 문항을 참고하여 구성요인을 개념화하고 스포츠코 칭정서지능에 적합한 문항을 1 차적으로 제작하였다. 내용 타당도 검증을 위해 전문가 집단은 현장지도자 3 인, 스포츠 심리학 전공자 3 을 포함한 총 6 인으로 구성하였다. 1 차로 추출된 문항은 정서지능 특성 모형을 토대로 문항의 적절성 과 현장 활용 가능성을 논의하였으며 3차례 내용수정 및 협 의과정을 거쳐 최종적으로 48 개의 예비문항으로'스포츠코 칭정서지능' 척도를 확정했다. 응답척도는 세분화하여 정교 한 답변을 받기 위해 7점 리커트(Likert)척도로, 1점(전혀 그렇지 않다) 7점(매우 그렇다)으로 구성하였다.

\section{자료수집}

연구참여자

스포츠코칭정서지능 척도개발에 필요한 자료수집 대상 
은 $\mathrm{OOO}$ 체육지도자 단체의 도움으로 전문운동선수를 대 상으로 지도하는 지도자를 대상으로 유목적 표집법 중 판단 표본추출법(Purposive sampling)에 의해 표집하였다. 판 단표본추출법은 연구목적에 근거하여 적합한 전문가나 특 정한 조직, 공동체 등 전문특성과 제한된 집단을 대상으로 연구를 시도할 때 유용한 표집방법이다(Chaiy \& Kim, 2016). 총 258명이 자발적으로 설문에 응답하였으며 설문 응답과정 가운데 불성실하거나 결측 응답한 22 명을 제외한 236명의 자료를 본 연구에 활용하였다.

연구참여자의 인구통계학적 특성은〈Table 1 ᄀ과 같다. 연구참여자의 성별은 남성 183 명(77.5\%) 여성 53명 (22.5\%)이었으며, 총 32개 종목의 지도자가 응답하였다. 32 개 종목 중 상위 5 개의 종목은 핸드볼 $13 \%$ (30명), 태권 도 10\%(23명), 복싱 9\%(22명), 정구 9\%(21명), 수영8\%(18 명) 및 스쿼시 $8 \%(18$ 명)로 나타났다. 지도자의 평균 선수경 력은 9.76 \pm 6.21 년이였고, 지도경력은 $12.24 \pm 8.14$ 년으 로 나타났다. 현재 지도자의 직위는 코치가 149 명(63.1\%) 으로 가장 높은 빈도를 보였으며, 감독 63명(26.7\%), 총 감 독 14 명 $(5.9 \%)$, 기타 10 명(4.2\%) 순이었다. 국가대표 지도 경험유무는 현재와 과거에 지도경험있음이 79명(33\%), 없 음이 155 명(65.7\%), 무응답 2명(8\%)인 것으로 나타났다. 지도선수의 성별은 남녀선수가 100 명(42.5\%), 남자선수가 79명(33.0\%), 여자선수가 57명(24.5\%)이었으며, 현재 지 도하고 있는 선수의 연령대는 고등학교선수 73명(31.0\%) 으로 가장 높은 빈도를 보였고 실업 및 프로선수 60명 (25.6\%), 중학교 선수 37명(15.8\%), 초등학교 선수 25명 (10.3\%), 대학교 선수 24명(9.9\%)으로 나타났다.

\section{자료수집절차}

자료수집은 $\mathrm{OOO}$ 체육지도자 단체 사무국에 의뢰하여 본 연구의 필요성과 목적을 설명하고 협조를 구하여 온라인 설문방법을 실시하였다. 전문 운동선수 지도자 회원의 이메 일을 통해 온라인 설문지 URL을 발송하여 자발적 의사에 의한 비대면 형태로 수집되었으며 설문 상단에는 본 연구의 목적, 설문 소요시간, 설문방법, 비밀보장 및 정보보호의 원 칙, 사례답례품 등에 관한 안내문을 기재하였다. 2021년 1 월 10 일 2월 10 일까지 약 한달 간 설문을 수거하였으며 자 기기입식 설문(Self-Administered Questionnaire)조사 형태로 진행되었다. 설문응답의 과소 - 과대보고, 거짓 및 결측 응답을 방지하고, 연구참여자의 시간과 노력에 대한
Table 1. Characteristic of participants

\begin{tabular}{|c|c|c|}
\hline \multicolumn{2}{|l|}{ Category } & \multirow{2}{*}{$\begin{array}{r}\mathrm{N}(\%) \text { or } \mathrm{M} \pm \mathrm{SD} \\
183(77.5 \%)\end{array}$} \\
\hline \multirow{2}{*}{ Gender } & Male & \\
\hline & Female & $53(22.5 \%)$ \\
\hline Athletic career (years) & & $9.76 \pm 6.21$ \\
\hline Coaching career (years) & & $12.24 \pm 8.14$ \\
\hline \multirow{4}{*}{ Position of Job } & Director & $14(5.9 \%)$ \\
\hline & Head Coach & $63(26.7 \%)$ \\
\hline & Coach & $149(63.1 \%)$ \\
\hline & Etc (e.g.Trainer) & $10(4.2 \%)$ \\
\hline \multirow{4}{*}{$\begin{array}{l}\text { Coaching experiences of } \\
\text { National athletes }\end{array}$} & Yes, Present & $23(9.7 \%)$ \\
\hline & Yes, Past & $56(23.7 \%)$ \\
\hline & No & $155(65.7 \%)$ \\
\hline & Nonresponse & $2(8 \%)$ \\
\hline \multirow{3}{*}{ Gender of athletes } & Male & $79(33.0 \%)$ \\
\hline & Female & $57(24.5 \%)$ \\
\hline & $\begin{array}{l}\text { Both Male and } \\
\text { Female }\end{array}$ & $100(42.5 \%)$ \\
\hline \multirow{6}{*}{ Affiliation of athletes } & $\begin{array}{l}\text { Professional } \\
\text { sports }\end{array}$ & $60(25.6 \%)$ \\
\hline & University & $24(9.9 \%)$ \\
\hline & High school & $73(31.0 \%)$ \\
\hline & Middle school & $37(15.8 \%)$ \\
\hline & $\begin{array}{c}\text { Elementary } \\
\text { school }\end{array}$ & $25(10.3 \%)$ \\
\hline & $\begin{array}{l}\text { Sports club } \\
\text { etc. }\end{array}$ & $17(7.4 \%)$ \\
\hline Total & & $236(100 \%)$ \\
\hline
\end{tabular}

보상으로 답례품을 희망하는 자에 한하여 설문 완료 후 추첨 을 통해 소정의 답례품을 제공하였다. 스포츠코칭정서지능 척도개발을 위한 자료수집과정 중 준거타당도(Criterion Validity) 검증을 위해 코칭효능감(Coaching Efficacy)척 도와 일반정서지능(Emotional Intelligence)척도 자료를 수집하였다.

\section{연구도구}

\section{코칭효능감 척도 (Coaching Efficacy)}

준거타당도 검증을 위해 Feltz et al.(1999)이 개발한 코 칭효능감척도를 번안절차(번역-역번역)에 따라 이중언어 사용자(한국어-영어)가 원본 영문척도를 한국어로 번한 후, 검토과정을 거쳐 수정 - 보완하여 사용하였다. 이 척도는 고 
등학교 지도자를 대상으로 개발되었으며 4요인(전술, 동기, 기술, 인성발달) 24 문항으로 본 연구에서는 7점 Likert 척도 (1점=전혀자신없다,-7점=완벽히 자신있다)로 응답되며 평 균 점수가 높을수록 지도자의 코칭효능감 정도가 우수한 것 을 의미한다. 원 문항에서 보고된 전체 내적합치도 계수 (Cronbach' $\alpha$ )는 .95이고 하위요인 인성발달(.88), 기술 (.89), 동기(.91), 전술(.88)로 나타났으며 재검사신뢰도 또 한 전체 .82로 높은 신뢰도를 보여주었다(Feltz et al., 1999). 본 연구에서 번안하여 사용한 척도는 하위요인 인성 발달(.88), 기술(.84), 동기(.94), 전술(.90)로 나타났으며 전체 .95로 높은 신뢰도 계수를 보였다.

\section{정서지능 척도(Emotional Intelligence)}

정서지능 척도는 Jang \& $\mathrm{Kim}(2019)$ 이 선행연구(Lee, Nam \& Kim, 2012; Nam, 2015)에서 타당도와 신뢰도가 검증된 Lane et al.(2009)의 스포츠 정서지능 질문지(SEIS: Sport Emotional Intelligence Scale)와 Davis, Lane, Devonport와 Scott(2011)의 단축형 정서지능 질문지 (BEIS: Brief Emotional Intelligence Scale)에서 5요인 10 문항을 추출하여 구성한 정서지능 척도를 사용하여 선수 들의 정시지능을 측정하였다. 자기정서평가(2문항), 타자정 서평가(2문항), 타자정서조절(2문항), 정서활용(2문항), 자 기정서조절(2문항)으로 구성되어 있다.

각 요인의 내적합치도 계수 $(\alpha)$ 는 .715에서 .757까지로 나타났다. 본 연구를 위해 지도자의 관점으로 문항을 수정 하여 사용하였으며, 각 하위요인 자기정서평가(.84), 타자 정서평가(.71), 자기정서조절(.47), 타자정서조절(.59), 정 서활용(.72)으로 나타났고 전체 내적 일치도 계수 $(\alpha)$ 는 .865로 높게 나타났다. 문항은 7점 Likert 척도(1=전혀그 렇지않다, 7 =매우 그렇다)로 응답되며, 평균 점수가 높을수 록 정서지능 능력과 활용성이 높음을 의미한다.

\section{분석절차}

본 연구의 자료는 IBM SPSS 23.0프로그램을 사용하 여 분석하였으며 구체적인 분석 방법은 다음과 같다.

첫째, 연구참여자의 일반적 특성은 빈도, 백분율, 평균과 표준편차로 산출하였고, 조사도구의 문항분석을 위해 문항 의 기술통계(평균, 표준편차, 왜도, 첨도, 수정된 항목-전체 상관계수 값)를 사용하였다.
둘째, 개발척도의 구인타당성 확인을 위한 탐색적 요인 분석(Exploratory Factor Anlaysis)을 실시하였다. 요인 추출은 주성분 분석 및 베리맥스(Varimax) 회전 방식을 사 용하였다. 탐색적 요인분석 전, $\mathrm{KMO}$ 표본적합성 측도와 Bartlett의 구형성 검정을 통해 탐색적 요인분석의 적합성 여부를 판단하였다. $\mathrm{KMO}$ 값은 0.80-0.89이상, Bartlett의 구형성검정은 유의수준(p<.05)이하일 때 적합한 것으로 판 단한다(Hoelzle \& Meyer, 2013; Kaiser,1974). 요인구 조는 고유값 1 이상, 요인공통성(Communality)값과 요인 부하량(Factor Loding)값이 .04이상 문항, 회전된 패턴행 렬에서 중복된 교차요인(Cross-loding)값이 .40미만인 문 항을 기준(Hair, Black, Babin \& Anderson, 2010)으로 이론적 타당성을 고려하여 문항을 추출하였으며 척도의 신 뢰도 평가는 내적일치도 계수(Cronbach's $\alpha$ )를 통해 확인 하였다.

셋째, 준거타당도 중 동시타당도(Concurrent Validity) 와 예측타당도(Predictive Validity) 검증을 위해 상관분석 을 통해 코칭효능감(Coaching Efficacy)척도와 정서지능 (Emotional Intelligence)척도와의 상관계수(Pearson's Correlation Coefficient)를 산출하였다. 상관계수의 평 가 기준은 Cohen(1992)의 근거에 따라 0.1 0.3은 낮은 상 관관계, $0.3 \sim 0.5$ 는 중간 상관관계, 0.5 이상은 높은 상관관 계로 판단하였다.

\section{연구결과}

\section{문항분석}

척도의 문항 양호도를 검사하기 위해 문항분석(평균, 표 준편차, 왜도, 첨도, 수정된 항목-전체 상관계수 값)을 실시 한 결과, 총 48문항의 평균점수 범위는 4.56 6.39점이었 고, 표준편차의 범위는 $0.71 ~ 1.69$ 점이었다. 왜도는 절대값 3 을 초과하지 않고 첨도는 절대값 8 혹은 10 이하 일 경우, 정 규분포로 간주한다(Kline, 2005). 본 연구결과에서는 문항 별 왜도는 $-0.34 \sim 2.21$, 첨도는 $-0.15 \sim 7.06$ 으로 분포하여 정규성 가정을 만족하였다. 문항-전체 간 상관계수의 분포 는 -.03 .70으로 나타났고 전체 문항의 내적 일관성 신뢰도 Cronbach's $\alpha$ 값이 .916였다. 각 문항 간의 수정된 항목-전 체 상관계수(Corrected Item-Total Correlation)가 .30 
미만인 경우, 해당 문항은 측정변수가 같은 요인에서 기여 도가 낮은 것으로 평가되고 .80이상인 경우는 불필요하게 문항의 유사성이 높은 것으로 간주된다(Nunnally \& Bernstein, 1994). .80이상 문항은 없었으며 .30미만 문항 은 4번(r=.254), 5번(r=.289), 8번(r=.296), 27번(r=.213), 29번(r=.265), 32번(r=.033), 35번(r=.254), 41번 (r=.200), 42번(r=.260) 9문항이였으나 8번 문항은 포함 기 준치에 근접하고 내용 타당성을 고려하여 요인분석에 포함 하였다. 총 8문항 $(4,5,27,29,32,35,41,42)$ 을 제거하였 으며 전체 40개 문항의 내적 일관성 신뢰도(Cronbach's $\alpha$ )값이 .927으로 매우 높게 나타났다〈Appendix 1〉.

\section{탐색적 요인분석 및 신뢰도}

탐색적 요인분석 전 요인분석의 적합성을 평가하기 위해 문항분석을 통해 선택된 40 문항의 $\mathrm{KMO}$ 와 Bartlett 구형성 검정을 확인하였다. $\mathrm{KMO}$ 값이 0.80-0.89일 경우 탐색적 요인분석을 위한 구조모형 선정이 유의미한 것으로 판단한다(Hoelzle \& Meyer, 2013; Kaiser,1974). 본 연구에서는 KMO값이 .900 으로 나타나 문항 간에 공통적인 잠재요인이 존재함을 확인하였으며 문항의 수와 표본의 수가 적절한 것으로 확인되었다. Barlett 구형성 검정에서 근사 카이제곱 값 은 $\left(X^{2}=4776.841, \mathrm{p}\right.$ < .001)으로 상관계수 행렬이 요 인분석에 적절한 것으로 나타났다.

요인구조는 문항 별 공통성이 .40미만인 문항은 제외하 고 요인 적재 값이 .40 이상, 교차요인적재량이 4.0 이하 인 문항만을 선별하였다. 1차 탐색적 요인분석 결과, 고유값 (Eigenvalue)이 1.0 이상인 요인의 수는 총 9개로 나타났 으나 설정 기준에 충족하지 못한 10 개의 문항 $(2,34,40$, $46,44,19,43,28,3,1)$ 을 제거 후, 30 문항을 확인한 결 과, 총 7 개 요인으로 분류되었다. 도출된 30 문항은 공통성 과 요인적재 값이 .40미만은 아니지만, 총 10 문항 $(37,21$, $18,12,26,14,11,15,16,17)$ 이 회전된 성분행렬에서 2 요인에 중복으로 속하여 척도의 이론적 개념과 타당성을 근 거로 제거하였다. 추출된 6개 요인이 적절한지 확인하기 위 해 2차 탐색적 요인분석을 시행하였다. 재분석 결과, $\mathrm{KMO}$ .836, Bartlette의 구형성 검정 값이 1999.758(p<.001)이 였으며, 6 개 요인에 의한 누적 설명력은 $68.49 \%$ 로 확인되 었다. 교차요인 적재량이 모두 .04보다 작게 나타났다
(Hoelzle \& Meyer, 2013). 최종적으로 〈Table 2〉에서 나 타난 바와 같이 6 개 요인, 20 문항이 추출되었고 각 요인별 설 명력은 요인 1이 $17.1 \%$, 요인 2가 $10.9 \%$, 요인 3이 $10.6 \%$, 요인 4 가 $10.5 \%$, 요인5 가 $10.1 \%$, 요인 6이 9.1\%로 나타났 다. 전체 요인에 대한 내적일관성 신뢰도(Cronbach's $\alpha$ )는 .851로 나타나 척도의 신뢰성도 검증되었다.

Table 2. The result of EFA

$(\mathrm{N}=236)$

\begin{tabular}{|c|c|c|c|c|c|c|}
\hline \multirow{2}{*}{ Items } & 1 & 2 & 3 & 4 & 5 & 6 \\
\hline & SA & $\mathrm{AO}$ & $\mathrm{OM}$ & UM & ER & SS \\
\hline 23 & .858 & .157 & .114 & .097 & .108 & .075 \\
\hline 24 & .857 & .100 & .252 & .110 & .072 & -.008 \\
\hline 25 & .820 & .111 & .231 & .139 & .085 & .139 \\
\hline 22 & .716 & .095 & -.020 & .112 & .109 & .055 \\
\hline 20 & .614 & .082 & .241 & .054 & .180 & .237 \\
\hline $10 \mathrm{R}$ & .134 & .840 & .074 & .028 & .026 & .023 \\
\hline 9R & .109 & .823 & .019 & .078 & .064 & .074 \\
\hline $13 R$ & .164 & .698 & .231 & -.085 & .041 & .181 \\
\hline 47 & .257 & .085 & .811 & .058 & .114 & .087 \\
\hline 48 & .175 & .105 & .787 & .103 & .144 & .130 \\
\hline 45 & .177 & .186 & .671 & .359 & .101 & .157 \\
\hline 30 & .070 & .079 & -.023 & .807 & .023 & .042 \\
\hline 31 & .087 & -.016 & .179 & .794 & .106 & .126 \\
\hline 33 & .233 & -.056 & .207 & .741 & .039 & .029 \\
\hline 8 & .086 & -.014 & .083 & .002 & .810 & -.018 \\
\hline 7 & .151 & .043 & .103 & .060 & .783 & .308 \\
\hline 6 & .187 & .134 & .141 & .133 & .749 & .161 \\
\hline 36 & .066 & .074 & .117 & .071 & .152 & .820 \\
\hline 39 & .269 & -.015 & .145 & .190 & .204 & .700 \\
\hline $38 \mathrm{R}$ & .045 & .397 & .080 & -.015 & .041 & .594 \\
\hline Eigenvalue & 3.430 & 2.178 & 2.128 & 2.105 & 2.028 & 1.827 \\
\hline$\%$ of variance & e 17.149 & 10.892 & 10.640 & 10.527 & 10.142 & 9.136 \\
\hline Cumulative $\%$ & 17.149 & 28.042 & 38.682 & 49.209 & 59.351 & 68.487 \\
\hline Cronbach's $\alpha$ & .874 & .763 & .785 & .737 & .752 & .600 \\
\hline
\end{tabular}

Extraction method: Principal Component Analysis

Rotation Method: Varimax

SA: Self-Awareness, AO: Awareness of Others,

OM:Optimism, UM: Utilization of Emotion

ER: Emotion Regulation, SS: Social Skills 
선별된 요인의 개념화를 위해 정서지능과 관련된 선행연 구와 문항의 공통된 의미를 고려하여 각 요인의 명칭을 부여 하였다. 요인1 자기정서인식(SA: Self-Awareness), 요인2 타인정서인식(AO: Awareness of Others), 요인3 긍정적 기대(OM:Optimism), 요인4 정서활용(UM: Utilization of Emotion), 요인5 정서조절(ER: Emotion Regulation), 요인6 사회기술(SS: Social Skills)로 각 요인을 명명하였다.

\section{준거타당도}

스포츠코칭정서지능 척도(Emotional Intelligence Scale in Sport Coaching: EISSC)에 대한 준거타당도 중 동시타당도와 예측타당도를 확인하기 위해 정서지능척도 (Jang \& Kim, 2019)와 코칭효능감척도(Feltz et al., 1999)간의 상관관계 분석((Pearson Correlation Coefficient Test)을 실시하였다. 개발된 스포츠코칭정서 지능 척도와 일반 정서지능척도와의 상관계수는 .713(p<.01)로 코칭효능감 척도와의 상관계수는 .647(p<.01)으로 나타나 동시타당도와 예측타당도가 수용 할 정도로 나타났다〈Table 3〉.

Table 3. Correlation between EISSC, EI and CE ( $\mathrm{N}=236)$

\begin{tabular}{|c|c|c|c|c|}
\hline \multicolumn{2}{|c|}{1} & \multirow[t]{2}{*}{2} & & \multirow[t]{2}{*}{3} \\
\hline 1 & 1 & & & \\
\hline 2 & $.713 * *$ & & 1 & \\
\hline 3 & $.647 * *$ & & $.663 * *$ & 1 \\
\hline
\end{tabular}

$* * p<.01$

1=Emotional Intelligence Scale in Sport Coaching

$2=$ Emotional Intelligence Scale

3=Coaching Efficacy Scale

\section{논 의}

본 연구에서는 전문 운동선수 지도자를 대상으로 스포츠 코칭정서지능 척도를 개발하고자 구성개념을 탐색하고 타 당도와 신뢰도를 평가하였다. 최종적으로 자기정서인식(5 문항), 타인정서인식(3문항), 긍정적기대(3문항), 정서활용 (3문항), 정서조절(3문항), 사회기술(3문항) 6요인 20문항 의 척도를 개발하였으며 이에 대한 논의는 다음과 같다.
전문 운동선수를 지도하는 지도자의 중요한 역할 중하나 는 선수들의 경기력 향상을 위한 효율적인 팀의 운영이며, 효율적인 팀을 만들기 위해서 지도자는 선수들과 신뢰관계 를 구축하여 촉진적인 관계(i.e., 선수-지도자 커뮤니케이 션, 상호작용 등)를 형성해야 한다(Chan \& Mallett, 2011; Hwang et al., 2013). 개인이 느끼는 정서와 정서표출은 대인관계를 형성하고 유지하는데 매우 중요하게 작용하기 때문에(Goleman, 1995; Neubauer \& Freudenthaler, 2005), 선수를 지도하는 지도자의 중요한 자질의 하나로 선 수들과의 유대관계형성과 경기력 향상에 영향을 미치는 정 서지능이 제안된다.

본 연구는 운동선수를 지도하는 지도자를 대상으로 스포츠코칭 정서지능을 개념화하고 척도를 개발하는 것 이다. 스포츠코칭 정서지능은 자신과 선수들의 정서 (e.g., 불안, 화, 기쁨, 성취감 등)를 잘 인식하고 선수들 을 지도하면서 유발되는 부정적인 감정을 잘 조절하여 긍정적인 팀 분위기를 형성하려는 것이다. 탐색적 요인 분석을 실시하여 자기정서인식(5문항), 타인정서인식(3 문항), 긍정적 기대(3문항), 정서활용(3문항), 정서조절 (3문항), 사회기술(3문항) 6요인 20문항의 척도를 개발 하였다. 자기정서인식(SA)은 지도자 자신이 경험하는 정서를 잘 구별하는 능력을 말하며 타인정서인식(AO) 은 선수들의 정서분위기를 잘 파악하는 지도자의 능력을 말 한다. 긍정적 기대 $(\mathrm{OM})$ 는 선수와 팀이 긍정적인 결과와 발 전이 있다는 믿음이며 정서활용(UE)은 긍정적인 감정상태 를 유지하여 촉진적인 지도능력을 말한다. 정서조절(ER)은 지도자 자신의 감정을 표출하지 않거나 긍정적인 정서로 전 환시킬 수 있는 능력으로 정의될 수 있다. 마지막으로 사회 기술(SS)은 선수들과의 관계를 잘 유지하기 위해 선수들을 격려하고 대화를 잘 이끌어나가는 능력을 말한다. 스포츠코 칭 정서지능의 6개의 하위요인은 일반정서지능 모형(i.e., Mayer, Caruso \& Salvoes, 1999; Mayer, Saloves \& Caruso, 2000; Petrides \& Furnham, 2004; Schutte et al., 1998)에서 제시하는 정서지능의 하위요인과 유사성이 높으며 측정문항은 전문스포츠지도자의 특수성에 맞게 구 성되어 본 척도를 사용한 연구결과의 타당성은 높을 것이 다.

스포츠 지도는 인간관계적 특성을 내포하고 있다. 개인 이 홀로 보고 듣고 행동하는 것이 아닌 지도를 받는 대상이 존재하며 집단 내 역동적인 관계(Group Dynamic)속에서 
이루어진다. 훈련에 대해 선수들이 느끼는 즐거움 (Enjoyment) 또는 지루함(Boring)과 같은 정서적 반응과 시합을 앞두고 느끼는 선수들의 불안감(Anxiety)등 을 지도 자들은 함께 인지하고 생활하고 있다. 선수들의 정서를 공 감하고 무엇을 그러한 정서를 유발하였는지를 이해하는 것 은 지도자의 중요한 역량이며 선수들과의 관계를 촉진적으 로 발전시키는 핵심요소이다(Chan \& Mallett, 2011). 지 도자들도 선수와 마찬가지로 다양한 정서를 경험하게 되고 이를 표출하게 된다. 경기에서 승리하거나 훈련의 집중도가 높았을 때 느끼는 희열(Joy)을 선수들과 교류하게 되기도 하 지만 화(Anger)와 실망(Disappointment)과 같은 부정적 스트레스를 경험하게 된다. 그러므로 스포츠팀 운영과 전문 선수들의 경기력 향상을 위한 지도자의 정서조절 및 활용능 력이 요구된다(Chan \& Mallett, 2011). 부정정서의 경험 은 인간이 지닌 교유한 기능이지만(Min et al., 2015)자신 의 감정을 숨기고 선수들을 격려하고 칭찬하는 등과 같이 부 정적인 정서를 팀 내의 긍정적인 분위기로 전환하는 정서조 절 및 활용 능력은 합리적인 의사결정, 효과적인 소통, 훈련 및 시합 집중도와 같이 팀과 선수 그리고 지도자의 발전적인 결과를 기대할 수 있다.

개발된 스포츠코칭정서지능 척도의 준거타당도를 확립 하기 위해 일반정서지능과 코칭효능감과의 상관관계분석을 실시한 결과 .71과 .65로 높은 수준의 정적관계를 나타냈 다. 유사변인인 일반정서지능과 관련변인인 코칭효능감과 의 유의미한 관계성은 개발된 척도의 준거타당도가 확립됨 을 시사해 준다. 최근 수정된 코칭효능감의 이론적 모형 (Boardley, 2018)에서 기존의 예측변인(i.e., 성공경험, 코 칭경험, 선수수준, 사회적지지)에 덧붙여 정서지능을 예측 변인으로 포함하였다. 경험적 연구를 통해서 정서지능의 하위요소인 정서조절과 사회기술은 동기효능감의 예측 변인으로 나타났으며, 기술효능감은 자기정서인식, 그 리고 인성발달효능감은 긍정적 기대와의 예측관계가 보 고되었다(Thelwell et al., 2008). Hwang et al.(2013)의 연구에서는 구조방정식 모형을 통해 정서 지능이 코칭효능감과 리더십행동간의 직접적인 관계성 을 설명하였다. 이러한 이론적 배경과 경험적 연구결과 들은 스포츠코칭 정서지능척도의 타당도를 높게 시사해 주고 있다. 지도자 자신의 감정을 잘 조절하고 긍정적인 정서를 유지 할 수 있는 지도자의 특성은 선수들과 발전 적인 관계형성에 도움이 되며 이는 자신이 선수를 지도
하는데 탁월함이 있고 자신의 지도과정에 대한 확실한 믿음을 형성하는 기초가 될 수도 있다. 이러한 지도자의 정서적 능력과 신념과 같은 개인의 특성은 선수들과의 촉진적인 관계 형성뿐만 아니라 선수들의 훈련 몰입도, 경기 수행력, 선수 만족도, 동기 등에 역동적으로 영향 을 미칠 수 있다(Horn, 2008; Jackson, Dimmock, Gucciardi \& Grove, 2011; Teques, Duarte \& Viana, 2019). 이러한 맥락을 자결성 이론에 적용하고 있다. 지도자의 정서지능이 선수들의 기본욕구만족 (Basic Need Satisfaction)에 미치는 영향을 탐색한 연구에서 지도자의 정서인식과 안정화 능력이 선수들의 유능감과 자율성을 유의미하게 예측하였다(Watson \& Kleinert, 2018). 또한 Kim et al.(2020) 연구에서는 지도자의 정서지능이 지도자의 자율성지지 코칭행동에 영향을 미치며 기본욕구만족에도 간접적으로 영향을 미 치는 것으로 제안하였다. 하지만 이러한 최근의 연구들 은 스포츠 코칭에 특화된 측정도구를 사용하지 않고 일 반적인 정서지능 검사 도구를 사용한 연구로 그 한계점 이 있으며 본 연구를 통해 개발된 척도는 추후의 스포츠 리더십, 지도자-선수관계, 팀 효율성 연구에 보다 타당 한 연구결과를 제시할 것으로 기대된다.

\section{결론 및 제언}

본 연구는 스포츠코칭상황에 특성화된 스포츠코칭정서지 능(Emotional Intelligence Scale in Sport Coaching: EISSC)척도를 개발하는 것에 목적을 두고 구조적 타당도와 준거타당도 검증 과정을 거쳐 다음과 같은 결론에 도달하였다.

첫째, 타당한 심리척도 개발과정을 거처 최종 6 요인 20 문항의 스포츠코칭정서지능척도(EISSC)가 개발되었으며 구조적 타당성과 준거타당도 그리고 신뢰도 분석 모두 척도 개발 기준에 적합한 것으로 나타났다. 본 연구를 통해 개발 된 EISSC 척도는 전문 스포츠 지도자가 팀 운영 및 운동선 수를 지도하는 과정에서 나타나는 다양한 관계적 특성에 내 포된 정서 경험, 활용, 조절 등의 정서적 능력을 평가할 수 있다. 전문스포츠지도자의 개인적 특성(Personal Trait)으 로 스포츠리더십, 지도자-선수관계, 팀 효율성, 선수만족도 등과 같은 연구에 활용될 수 있다.

다만, 스포츠심리학 연구에서 완벽한 심리측정도구는 있 
을 수 없다. 이번 연구를 통해 개발된 6개의 하위요인이 전문 운동선수를 지도하는 과정의 모든 정서적 능력을 포함한다 고 단언할 수 없을 것이다. 따라서, 후속연구에서는 6개의 구 성요소 이외에도 정서이해(Understanding of Emotion), 정서적 안녕감(Emotional Well-being)과 같이 기존의 일 반 정서지능의 구성요소로 사용되는 것도 추후연구를 통해 보완될 수 있다. 또한, 문항 선택과정에서 타인정서인식 문 항은 역 코딩문항으로만 남게 되었다. 문항개발 과정에서 역 코딩문항을 균형 있게 개발하였으나 신뢰도와 타당도 확 보를 위한 선별과정에서 대부분의 역 코딩 문항이 삭제되는 제한점이 존재하며 이를 보완하는 수정된 스포츠 정서지능 척도개발이 추후연구로 제안된다. 또한, 스포츠지도의 일반 적 특성을 기초하여 문항을 제작하여 종목특성과 선수들의 성별과 나이와 같은 개인적 특성은 반영되지 못한 제한점이 있다. 따라서, 팀 스포츠와 개인 종목, 기록경기와 구기 등과 같은 종목특성에 따른 개발과 분석이 요구되며, 특히 성별 과 운동수준에 따른 차이를 구별하는 연구가 필요할 것으로 생각된다.

마지막으로, 스포츠 정서지능척도는 이론개발을 넘어 현 장 활용이 기대된다. 정서지능은 현장지도자가 실제 소지해 야할 핵심역량으로 바라보는 관점이 필요하며 지도자의 정 서지능에 관한 현 수준을 파악하고 역량강화 교육을 통해 지 도자의 코칭능력을 향상시키기 위한 평가 자료로 사용될 수 있다.

\section{참고문헌}

Austin, E. J., Saklofske, D. H., Huang, S. H. S., \& McKenney, D. (2004). Measurement of trait emotional intelligence: Testing and cross-validating a modified version of Schutte et al.'s (1998) measure. Personality and Individual Differences, 36(3), 555-562.

Bar-On, R. (1997). The Emotional Quotient Inventory (EQ-i): a test of emotional intelligence. Toronto, Canada: Multi-Health Systems, Inc.

Boardley, I. D. (2018). Coaching effiacy research: learning from the past and looking to the future. International Review of Sport and Exercise Psychology, 11, 214-237.

Caruso, D. R., Mayer, J. D., \& Salovey, P. (2002). Emotional intelligence and emotional leadership. In R.E. Riggio, S.E. Murphy, \& F. J. Pirozzolo (Eds), Muliple intelligences and leadership. (p. 55-74), Mahwah, N.J.: Lawrence Erlbaum Associates.

Chaiy, S., \& Kim, J. (2016). Social Welfare Law (Korean Edition, 4th) Bnmbooks.

Chan, J. T., \& Mallett, C. J. (2011). The value of emotional intelligence for high performance coaching. International Journal of Sports Science \& Coaching, 6, 315-328.

Cho. C., \& Kang, K. (2016). The structural relationship among private kindergarten director's emotional leadership, kindergarten teacher's emotional intelligence, teacher's efficacy, and job satisfaction. Journal of Learner-Centered Curriculum and Instruction, 16(4), 741-767.

Choi, M., \& Kim, S. (2014). The development of an emotional intelligence scale in youth players. Journal of Coaching Development. 16(4), 61-74.

Cohen, J. (1992). A power primer. Psychological Bulletin, $112(1), 155-159$.

Davis, K. A., Lane, A. M., Devonport, T. J., \& Scott, J. A. (2011). Validity and reliability of a Brief Emotional Intelligence Scale (BEIS-10). Journal of Individual Differences, 31(4), 198-208.

Feltz, D. L., Chase, M. A., Moritz, S. E., \& Sullivan, P. J. (1999). A conceptual model of coaching efficacy: preliminary investigation and instrument development. Journal of Educational Psychology, 91, 765-776.

Goleman, D. (1995). Emotional intelligence: Why it can matter more than IQ. New York, NY: BantamBooks

Goleman, D., Boyatzis, R., \& Mckee, A. (2002). Primal leadership: Learning to lead with emotional intelligence. Boston: Harvard Business Press.

Gould, D., Greenleaf, C., Guinan, D., \& Chung, Y. (2002). A survey of U.S. Olympic coaches: Variables perceived to have influenced athlete performances and coach effectiveness. The Sport Psychologist, 16(3), 229-250.

Grace, K. (1988). Successful vs. unsuccessful coaches and athletes. Track Technique, 104, 3325.

Hair, J. F., Black, W. C., Babin, B. J., \& Anderson, R. E. (2010). Multivariate data analysis: Aglobal perspective. 7th ed. Upper Saddle River, NJ: Pearson Prentice Hall; p. 109-136.

Hoelzle, J. B., \& Meyer, G. J. (2013). Exploratory factor analysis: Basics and beyond. In Weiner, I. B., Schinka, J. 
A., Velicer, W. F. (Eds.), Handbook of psychology: Research methods in psychology (Vol. 2, 2nd ed., pp. 164-188). Hoboken, NJ: Wiley.

Horn, T. S. (2008). Coaching effectiveness in the sport domain. In T.S. Horn (Ed.), Advances in sport psychology (3rd ed., pp. 239-265). Champaign, IL: Human Kinetics

Hwang, S., Feltz, D.L., \& Lee, J.D. (2013). Emotional intelligence in coaching: Mediation effect of coaching efficacy on the relationship between emotional intelligence and leadership style. International Journal of Sport and Exercise Psychology, 11, 1-15.

Jackson, B., Dimmock, J. A., Gucciardi, D. F., \& Grove, J. R. (2011). Personality traits and relationship perceptions in coach-athlete dyads: Do opposites really attract? Psychology of Sport and Exercise, 12, 222-230.

Jang, B. \& Kim, S. (2019). A structural relationships between college athletes' perceived coaching behaviors, affective responses, emotional intelligence, and performance effort/persistence. Korean Journal of Sport Psychology, $30(2), 1-13$.

Kaiser, H. F. (1974). An index of factorial simplicity. Psychometrika, 39(1), 31-36.

Kim, B. (2009). The relationship among emotional leadership of elite athlete coach, athletes'emotions, team climate and team effectiveness. Ph.D. Dissertation. Dankook University.

Kim, S., \& Choi, M. (2014). An exploration of the causal relationship among transactional leadership, coaches' emotional intelligence, and athlete satisfaction in soccer team. The Korea Contents Association, 14(9), 450-462.

Kim, S.., Hwang , S., \& Kim, B. (2020). Coaches' emotional intelligence and athletes' psychological need satisfaction in taekwondo: Coaching behaviour as a mediator. Archives of Budo, 16.

Kline, R. B. (2005). Principles and Practice of Stuctural Equation Modeling. New York: Guildford Press.

Kobe, L. M., Reiter-Palmon, R., \& Rickers, J. D. (2001). Self-Reported leadership experiences in relation to inventoried social and emotional intelligence. Current Psychology, 20, 154-163.

Lane, A. M., Meyer, B. B., Devonport, T.J ., Davies, K. A., Thelwell, R., Gobinder, S., Diehl, C.D., Wilson, M., \& Weston, N. (2009). Validity of the emotional intelligence scale for use in sport, Journal of Sports Science \& Medicine, 8(2), 1-7.

Lee, M., Nam, J. \& Kim, B. (2012). A structural validation of the sport emotional intelligence scale for college athletes. The Korean Journal of Measurement and Evaluation in Physical Education and Sports Science, 14(3), 33-46.

Lim, J. (2014). A study related to the emotional intelligence of counselors, counseling relationships, and counseling outcomes. Ph.D. Dissertation. The Catholic University of Korea.

Matthews, G., Zeidner, M., \& Roberts, R.D. (2007). Emotional intelligence: consensus, controversies, and questions. In G. Matthews., M. Zeidner., \& R. D. Roberts (Eds), The science of emotional intelligence: knows and unknowns (pp. 3-46). New York: Oxford University Press.

Mayer, J. D., Caruso, D., \& Salovey, P. (1999). Emotional intelligence meets traditional standards for an intelligence, Intelligence, 27(4), 267-298.

Mayer, J. D., Salovey, P., Caruso, D. Sitarenios, G. (2001). Emotional intelligence as a standard intelligence. Emotion. 1(3), 232-42

Mayer, J. D., Salovey, P., \& Caruso, D. (2000). Models of emotional intelligence. In R. J. Sternberg (Ed.), Handbook of intelligence (p. 396-420). Cambridge University Press.

Meyer, B. B., \& Fletcher, T. B. (2007). Emotional intelligence: A theoretical overview and implications for research and professional practice in sport psychology. Journal of Applied Sport Psychology, 19, 1-15.

Min, K., Lee, O., Lee, J., Kim, M., Jang, S., \& Kim, M. (2015). Emotion. Cengage Learning.

Nam, J. (2015). Item goodness-of-fit of emotional intelligence scale for college athlete. The Korean Society of Sports Science. 24, 671-684.

Nunnally, J. C., \& Bernstein, I. H. (1994). Psychometric theory (3rd ed.). pp. 447-490. New York McGraw-Hill.

Neubauer, A. C., \& Freudenthaler, H. H. (2005). Models of emotional intelligence. In R. Schulze \& R. D. Roberts (Eds.). Emotional intelligence: an international handbook (pp. 31-50). Cambridge, MA: Hogrefe \& Huber.

Oh, J. (2008). Effects of emotional leadership in tennis leaders on coaching efficiency. Master's thesis. Dankook University.

Petrides, K. V., \& Furnham, A. (2001). Trait emotional 
intelligence: Psychometric investigation with reference to established trait taxonomies. European Journal of Personality, 15, 425-448.

Petrides, K. V., \& Furnham, A. (2004). Technical manual of the trait emotional Intelligence questionnaire (TEIQue). London: University of London, Institute of Education.

Pérez, J. C., Petrides, K. V., \& Furnham, A. (2005). Measuring TraitEmotional Intelligence. In R. Schulze \& R. D. Roberts (Eds.), Emotional intelligence: An international handbook (p. 181-201). Hogrefe \& Huber Publishers. with reference to established trait taxonomies. European Journal of Personality, 15, 425-448.

Rosete, E., \& Ciarrochi, F. (2005). Emotional intelligence and its relationship to workplace performance outcomes of leadership effectiveness. Leadership \& Organization Development Journal, 26, 388-399.

Schutte, N. S., Malouff, J. M., Hall, L. E., Haggerty, D. J., Cooper, J. T., Golden, C. J., \& Dornheim, L. (1998). Development and validation of a measure of emotional intelligence. Personality and Individual Differences, 25,
167-177.

Teques, P., Duarte, D., \& Viana, J. (2019). Coaches' Emotional intelligence and reactive behaviors in soccer matches: Mediating effects of coaches efficacy beliefs. Frontiers in Psychology, 10, 1629

Thelwell, R. C., Lane, A. M., Weston, N. J. V., \& Greenlees, I.A. (2008). Examining relationships between emotional intelligence and coaching efficacy. International Journal of Sport and Exercise Psychology, 6, 224-235.

Watson, M., \& Kleinert, J. (2018). The relationship between coaches' emotional intelligence and basic need satisfaction in athletes. Sports Coaching Review, 8(3), 224-242.

Wong, C. S., \& Law, K. S. (2002). The effects of leader and follower emotional intelligence on performance and attitude: An exploratory study. Leadership Quarterly, 13, 243-274.

Wooden, J., \& Jamison, S. (2005). Wooden on leadership. New York: McGraw-Hill. 


\title{
스포츠코칭정서지능 척도 개발
}

\author{
황승현 ${ }^{1}$, 김보람 ${ }^{2}$, 강호석 $^{3}$ \\ ${ }^{1}$ 경북대학교 조교수 \\ 2경북대학교 박사과정 \\ ${ }^{3}$ 대한스쿼시연맹 국가대표 감독
}

[목적] 본 연구의 목적은 정서지능의 특성모형을 기반으로 스포츠 현장과 코칭상황에 특성화된 스포츠코칭 정서지능 측정도구(Emotional Intelligence Scale in Sport Coaching: EISSC)를 개발하고 개발된 척도의 구조 적타당성과 준거타당도를 검증하는 것이다. [방법] 연구참가자는 236명의 전문운동선수 지도자로 유목적 표 집법 중 판단표본추출법에 의해 표집하였으며 이메일을 통해 설문에 참여하였다. 예비 척도 48 문항 중 문항분 석 후 총 40문항을 탐색적 요인분석을 실시하였으며 준거타당도는 코칭효능감 및 일반정서지능 척도와의 상 관관계(Pearson's correlation)에 의해 확인하였고 신뢰성은 내부 일관성인 크론바흐의 알파 계수로 평가하였 다. [결과] 스포츠코칭정서지능(EISSC)의 탐색적 요인분석 결과, 6 개요인(자기정서인식, 타인정서인식, 긍정적 기대, 정서활용, 정서조절, 사회기술)20문항이 최종선별되었으며 6개요인은 설명력 $68.49 \%$ 를 나타냈다. 또한, 코칭효능감(r=.713) 및 일반정서지능 $\mathrm{I}(\mathrm{r}=$.647)과의 상관도를 확인함으로써 준거타당도가 뒷받침되었으며 신뢰 도는 Cronbach's alpha 계수 .851로 나타났다. [결론] 스포츠코칭정서지능척도는 지도자의 스포츠환경 및 지도과정에서 나타나는 특화된 정서지능을 객관적으로 평가하는데 활용할 수 있다.

주요어: 정서지능, 스포츠코칭, 엘리트스포츠, 코치, 요인분석, 척도 
Appendix 1. Item-Analysis

$(\mathrm{N}=236)$

\begin{tabular}{|c|c|c|c|c|c|c|}
\hline Item & $\mathrm{M}$ & SD & Skewness & Kurtosis & $\begin{array}{l}\text { Corrected item-total } \\
\text { correlation }\end{array}$ & $\begin{array}{c}\text { Cronbach's } \alpha \\
\text { if item is deleted }\end{array}$ \\
\hline 1 & 6.06 & .881 & -.975 & 1.038 & .621 & .913 \\
\hline 2 & 6.31 & 1.006 & -2.208 & 7.059 & .413 & .914 \\
\hline 3 & 6.26 & .797 & -.957 & .780 & .652 & .913 \\
\hline $4 \mathrm{R}^{*}$ & 4.93 & 1.686 & -.595 & -.794 & .254 & .917 \\
\hline $5 R^{*}$ & 5.36 & 1.628 & -1.140 & .483 & .289 & .916 \\
\hline 6 & 5.37 & 1.309 & -.800 & .453 & .507 & .913 \\
\hline 7 & 5.70 & 1.128 & -1.528 & 3.932 & .497 & .913 \\
\hline 8 & 5.82 & 1.316 & -1.579 & 2.700 & .296 & .915 \\
\hline 9R & 4.56 & 1.671 & -.342 & -.972 & .403 & .915 \\
\hline $10 \mathrm{R}$ & 4.92 & 1.537 & -.657 & -.398 & .401 & .914 \\
\hline 11 & 5.74 & .992 & -.887 & 1.257 & .415 & .914 \\
\hline 12 & 5.82 & .907 & -.806 & 1.382 & .458 & .914 \\
\hline 13R & 5.03 & 1.457 & -.560 & -.523 & .486 & .913 \\
\hline 14 & 5.94 & .970 & -.755 & .151 & .530 & .913 \\
\hline 15 & 6.00 & .846 & -.639 & .344 & .696 & .912 \\
\hline 16 & 5.95 & .849 & -.660 & 1.030 & .588 & .913 \\
\hline 17 & 6.34 & .712 & -.752 & -.148 & .512 & .914 \\
\hline 18 & 6.01 & .853 & -.522 & -.212 & .680 & .912 \\
\hline 19 & 5.72 & .909 & -.265 & -.547 & .625 & .913 \\
\hline 20 & 6.05 & .844 & -.654 & .093 & .611 & .913 \\
\hline 21 & 5.80 & .926 & -.630 & .221 & .560 & .913 \\
\hline 22 & 5.75 & 1.048 & -1.004 & 1.565 & .471 & .914 \\
\hline 23 & 5.98 & .894 & -.759 & .969 & .607 & .913 \\
\hline 24 & 6.10 & .912 & -1.051 & 1.560 & .597 & .913 \\
\hline 25 & 6.21 & .858 & -.944 & .651 & .647 & .913 \\
\hline 26 & 5.62 & 1.039 & -.630 & .252 & .512 & .913 \\
\hline $27 *$ & 5.47 & 1.667 & -1.206 & .532 & .213 & .917 \\
\hline 28 & 5.93 & .922 & -.710 & .377 & .650 & .912 \\
\hline $29 *$ & 5.44 & 1.499 & -1.142 & .998 & .265 & .916 \\
\hline 30 & 5.05 & 1.494 & -.798 & .451 & .305 & .916 \\
\hline 31 & 5.43 & 1.368 & -1.018 & .969 & .389 & .914 \\
\hline $32 *$ & 4.56 & 1.661 & -.606 & -.430 & .033 & .919 \\
\hline 33 & 5.60 & 1.256 & -1.100 & 1.410 & .413 & .914 \\
\hline 34 & 5.75 & 1.317 & -1.318 & 1.717 & .399 & .914 \\
\hline $35^{*}$ & 4.98 & 1.706 & -.736 & -.286 & .254 & .917 \\
\hline 36 & 6.20 & .997 & -1.370 & 1.815 & .449 & .914 \\
\hline $37 \mathrm{R}$ & 5.27 & 1.604 & -.862 & -.266 & .434 & .914 \\
\hline $38 \mathrm{R}$ & 4.74 & 1.587 & -.367 & -.814 & .428 & .914 \\
\hline 39 & 5.89 & .930 & -.804 & .916 & .558 & .913 \\
\hline 40 & 5.06 & 1.356 & -.379 & -.554 & .361 & .915 \\
\hline $41 \mathrm{R}^{*}$ & 4.89 & 1.605 & -.504 & -.675 & .200 & .917 \\
\hline $42 *$ & 4.77 & 1.429 & -.500 & -.153 & .260 & .916 \\
\hline 43 & 5.92 & 1.171 & -1.646 & 3.685 & .437 & .914 \\
\hline $44 \mathrm{R}$ & 5.23 & 1.590 & -1.003 & .332 & .402 & .914 \\
\hline 45 & 6.25 & .949 & -1.232 & .993 & .596 & .913 \\
\hline $46 \mathrm{R}$ & 5.87 & 1.465 & -1.498 & 1.534 & .455 & .914 \\
\hline 47 & 6.39 & .855 & -1.491 & 2.049 & .548 & .913 \\
\hline 48 & 6.37 & .807 & -1.160 & .933 & .568 & .913 \\
\hline
\end{tabular}

*해당 문항은 전체 항목에서 상관계수가 낮아 요인분석에서 제외한 문항임 (총 8문항) 
Appendix 2.

\section{스포츠코칭정서지능 척도 (Emotional Intelligence Scale in Sport Coaching)}

지도자 자신뿐만 아니라 선수와 팀의 정서적인 문제를 잘 관리하는 것은 지도자의 중요한 능력 중에 하나입니다. 스포츠 지도 상황을 생각하며 각 문항을 읽고 가장 적절한 것에 표기해주십시오.

\begin{tabular}{|c|c|c|c|c|c|c|c|c|c|}
\hline \multirow[t]{2}{*}{ 문항 } & \multirow[t]{2}{*}{$\begin{array}{l}\text { 원 } \\
\text { 문항 }\end{array}$} & \multirow[t]{2}{*}{ 내용 } & \multicolumn{4}{|c|}{$\begin{array}{l}\text { 전혀 } \\
\text { 그렇지 } \\
\text { 않다 }\end{array}$} & \multicolumn{3}{|c|}{$\begin{array}{l}\text { 매우 } \\
\text { 그렇다 }\end{array}$} \\
\hline & & & 1 & 2 & 3 & 4 & 5 & 6 & 7 \\
\hline 1 & 20 & 나는 어려움을 인지했을 때 유사한 어려움을 내가 어떻게 겪고 극복하였는지를 생각한다. & & & & & & & \\
\hline 2 & 22 & 나는 선수들에게 보내는 나의 비언어적 메시지(표정, 몸짓 등)를 인식하고 있다. & & & & & & & \\
\hline 3 & 23 & 나는 나의 감정이 왜 변화하는지를 알고 있다. & & & & & & & \\
\hline 4 & 24 & 나는 무엇이 나를 기분 나쁘게 하는지를 알고 있다. & & & & & & & \\
\hline 5 & 25 & 나는 무엇이 나를 기쁘게 하는지를 알고 있다. & & & & & & & \\
\hline $6 \mathrm{R}$ & 9R & 나는 선수들의 대화가 진심인지를 구별하기 어려울 때가 있다. & & & & & & & \\
\hline $7 \mathrm{R}$ & $10 \mathrm{R}$ & 나는 선수들의 표정을 잘못 읽는 경우가 있다. & & & & & & & \\
\hline $8 \mathrm{R}$ & $13 \mathrm{R}$ & 나는 선수들이 왜 그렇게 느끼는지 이해하기가 어렵다. & & & & & & & \\
\hline 9 & 45 & 나는 대체로 좋은 일(승리, 선수의 성장)이 일어나는 것을 기대한다. & & & & & & & \\
\hline 10 & 47 & 나는 훈련과 시합 전략이 좋은 결과로 이어질 것으로 기대한다. & & & & & & & \\
\hline 11 & 48 & 나의 팀과 선수들은 발전적이다. & & & & & & & \\
\hline 12 & 30 & 나는 기분이 좋을 때 팀의 문제가 쉽게 해결된다. & & & & & & & \\
\hline 13 & 31 & 나는 좋은 기분을 이용해서 팀의 어려운 문제가 해결되도록 노력한다. & & & & & & & \\
\hline 14 & 33 & 나의 좋은 감정은 훈련과 시합을 위한 새로운 전략을 찾는데 도움이 된다. & & & & & & & \\
\hline 15 & 6 & 나는 팀과 선수를 위해 나쁜 감정을 좋은 감정 상태로 변화시킬 수 있다. & & & & & & & \\
\hline 16 & 7 & 나는 팀 분위기가 좋지 않을 때 긍정적인 정서를 발산시킬 수 있다. & & & & & & & \\
\hline 17 & 8 & 나는 선수 개개인에게 사적인 감정을 드러내지 않는다. & & & & & & & \\
\hline 18 & 36 & 나는 선수들이 잘 했을 때 칭찬을 자주 한다. & & & & & & & \\
\hline $19 \mathrm{R}$ & $38 \mathrm{R}$ & 선수들은 나에게 자신의 생각과 감정을 말하기 어렵다고 한다. & & & & & & & \\
\hline 20 & 39 & 나는 선수가 기분이 다운될때 기분이 나아지도록 도와준다. & & & & & & & \\
\hline
\end{tabular}

* $\mathrm{R}$ 은 역채점 문항임 자기정서인식 $(1,2,3,4,5)$ 정서활용 $(12,13,14)$,
타인정서인식(6R, 7R, 8R),

정서조절 $(15,16,17)$,
긍정적기대 $(9,10,11)$,

사회기술(18, 19R, 20) 